\title{
Pseudomonas Exotoxin Immunoconjugate
}

National Cancer Institute

\section{Source}

National Cancer Institute. Pseudomonas Exotoxin Immunoconjugate. NCI Thesaurus. Code $C 78532$.

An immunotoxin containing epitope of Pseudomonas exotoxin (PE) with immunotherapeutic property. PE, a peptide toxin of 613 amino acids, consists of 3 functional domains: an amino-terminal receptor-binding domain, a middle translocation domain, and a carboxyl-terminal ADP-ribosylation domain. The last 5 carboxyl-terminal amino acids, Arg-Glu-Asp-Leu-Lys, are critical for its cytotoxic action. 